with similar trajectories for L2 English, with declining trajectories for L3s emerging. L2 English was seen to have a negative impact on motivation to learn L3 French, German and Spanish. Light is shed on the cognitive processes in situations where language speaking/using self-concepts come into contact and how L3 self-concepts are appraised in relation to L2 counterparts.

The examiners remarked that this 'very important thesis builds on recent developments in research on motivation in language learning, applying these to L3 acquisition. It makes a particularly valuable contribution to our understanding of the relationship between L2 and L3 acquisition and opens up a number of interesting avenues for further exploration, not least with respect to gender differences and the role of the ideal self. The research is well conceived, methodologically rigorous, analytically convincing and persuasively argued. Its relevance extends far beyond Sweden, and the proposals for further research hold out excellent prospects for further deepening our understanding in this important area'.

Lang. Teach. (2014), 47.4, 412-413 $\quad$ (C) Cambridge University Press 2014 doi:10.1017/S0261444814000226

\title{
Christopher Brumfit Ph.D./Ed.D. Thesis Award 2014
}

\section{Sponsored by Cambridge University Press and promoted by Language Teaching}

Aim To recognise doctoral thesis research that makes a significant and original contribution to the field of SLA and/or foreign/second language teaching and learning.

Award Cambridge University Press books to the value of $\mathcal{E}_{500}$

Eligibility To be considered for the award:

- The candidate's institution must have accepted the thesis for the Ph.D./Ed.D. NO MORE THAN TWO YEARS BEFORE the date of the award application.

- The research must have been completed as part of the requirements for a doctoral degree or its equivalent at a university.

- Although the thesis under consideration must be in English, the research may be related to work concerning any second language.

- Candidates should not have applied for the award on a previous occasion.

Application Process In the first instance, applicants must submit the following:

- Two files: One MS WORD file containing a summary of the thesis, not to exceed 17 double-spaced pages including references, font size 12, AND A SEPARATE MS WORD FILE CONTAINING A 150-WORD ABSTRACT of the thesis. Both files should be clearly labelled with the candidate's name, and neither file should exceed $2 \mathrm{MB}$.

Preparing your summary Care should be taken in drafting the summary so that the referees are provided with as detailed a report as possible on the work undertaken. 
Candidates should prepare the text for an audience that may not be expert in all the specific concepts or methods used in your specialist topic area.

The summary should include a brief description of the theoretical background of the research and (where appropriate) specify the research questions, the research methods (including data analyses) used and why these were chosen, the results, and implications of these outcomes. Examiners will pay particular attention to: whether the study makes a significant and original contribution to knowledge and understanding of the field concerned; whether the problem tackled emerges naturally and clearly from the review of the theoretical background of the research; whether the method is presented in sufficient detail and with enough explanation as to why the methods used were chosen; whether the analytic methods used are justified and shown to be sufficient for the task and if these are clearly linked to the explicit hypotheses, predictions, or questions which formed part of the stated research problem; whether the discussion and/or conclusion evaluates the project's contribution to the local and wider field of research; finally, whether there is a clear and significant contribution to the field of SLA and/or FL teaching and learning.

- Proof of The AWARd of The Degree by the candidate's university. This can be a scanned copy in pdf form of the degree certificate or a scanned official letter/transcript from the university in question stating clearly the date of conferment of the degree.

Only electronic applications are accepted.

\section{Evaluation criteria}

- Scholarly or professional significance to the field of second or foreign language learning/teaching

- Originality and creativity

- Quality of presentation.

\section{Dates}

30 November 2014 Deadline for receipt of summary and abstract and official proof of thesis acceptance

20 February 2015 Feedback given to all candidates and call for electronic submission of theses of short-listed candidates

3 March 2015 Deadline for receipt of theses

1 August 2015 Announcement of award winner by the Editorial Board of Language Teaching

\section{Contact details for application and further information}

Dr Graeme Porte, Editor Language Teaching

E-mail: editorlanguageteaching@gmail.com 